\title{
SOCIEDADES FRATERNAS E A LIVRE CIRCULAÇÃO DE PESSOAS NA EUROPA
}

\section{FRATERNAL PARTNERSHIPS AND THE FREE MOVEMENT OF PERSONS IN EUROPE}

\section{MAURO DE PAULA BRANCO}

Mestrando do Programa de Mestrado em Direito Empresarial e Cidadania do Centro Universitário Curitiba (UNICURITIBA).

\section{RESUMO}

O presente artigo científico possui como objetivo a demonstração dos elementos que compõem o Direito Fraterno, bem como a sua aplicabilidade nas relações entre as coletividades europeias. Para tanto, em um primeiro momento a atenção se volta para uma breve análise da sociedade fraterna na perspectiva do princípio universal da dignidade da pessoa humana, passando por um breve estudo dialético entre situações conflituosas e desenvolvimento do Direito humanitário.

PALAVRAS-CHAVE: Comunidade; Direito Fraterno; Dignidade da Pessoa Humana; Direito Cosmopolita; Coletividade; Espaço Schengen.

\begin{abstract}
The present scientific article aims to demonstrate the elements that make up the Fraternal Law, as well as its applicability in the relations between the European collectivities. In order to do so, at first the attention turns to a brief analysis of the fraternal society in the perspective of the universal principle of the dignity of the human
\end{abstract}




\section{Personalidade Acadêmica Homenageada:}

Carlos Aurélio Mota de Souza (Universidade Ibirapuera - UNIB)

person, passing through a brief dialectical study between conflicting situations and development of humanitarian law.

KEYWORDS: Community; Fraternal Law; Dignity of Human Person; Cosmopolitan Law; Schengen Area; Collectivity.

\section{INTRODUÇÃO}

Uma sociedade fraterna, livre de preconceitos, discórdias e submissões. Talvez este seja o ideal de qualquer Estado. Mas a questão é complexa, tendo em vista que envolve diversos personagens, sendo que, na falha de um deles, todo o ideal de harmonia pode se encontrar em situação de risco. Neste momento, cabe aos demais agentes ampararem aqueles que se encontram em situação de vulnerabilidade em face da coletividade em que estão inseridos. Assim ganha vida o Direito Fraterno, capaz de promover a amorosidade nas relações sociais e jurídicas.

Dessa forma, optou-se por trazer por meio do presente estudo os elementos que conduzem para o surgimento desse chamado Direito Fraternal, que ganha sustentação através do princípio da fraternidade, que traz à tona as iniciativas solidárias, seja entre os particulares, seja emanado do Poder Público.

Para demonstrar a viabilidade de sua aplicação, o presente estudo aderiu ao plano princípio da dignidade da pessoa humana, de modo a reforçar o direito à vida, não só no tocante à sobrevivência, mas também condizente com a existência digna e harmoniosa entre os indivíduos de nações distintas, entre indivíduos de outras nações e coletividades e entre indivíduos e Estados. Assim, o Direito Fraterno ganha respaldo naquilo que Kant convencionou chamar de Direito Cosmopolita, sendo essa peça fundamental para as boas relações internacionais. Ainda que breve, a dialética é essencial para demonstrar quais as peculiaridades que fazem do Direito Fraterno um a busca perene capaz de balancear a igualdade e a liberdade.

Por fim, reforça-se a concepção do Direito Fraterno com o exemplo da livre circulação de pessoas na Europa, no denominado Espaço Schengen, derivado do 


\section{Personalidade Acadêmica Homenageada:}

Carlos Aurélio Mota de Souza (Universidade Ibirapuera - UNIB)

acordo que leva o mesmo nome. A experiência, embora delicada por questões de soberania e de crises diplomáticas, tem sido uma prova de que uma sociedade fraterna e solidária não se perfaz em ameaça aos Estados soberanos, mas ao contrário, podem construir um forte alicerce para o desenvolvimento social e consequentemente para a paz e a harmonia entre as nações.

\section{O DIREITO FRATERNO}

Quando se está a falar em "Direito Fraterno", com naturalidade surge a sensação de estranheza por boa parte dos destinatários, na medida em que se trata de um instituto esquecido até mesmo pelos ordenamentos jurídicos, estando fora das vistas dos legisladores que pouco produzem sobre a fraternidade, embora pudesse haver farta legislação a respeito. Não se sabe ao certo o porquê da marginalização da fraternidade, mas o fato é que, a sua ausência, ainda que pouco percebida, é capaz de gerar impactos não só nas relações entre Estado e coletividade, mas também dentro da própria sociedade, na qual não se incute a perspectiva fraternal do Direito. No entanto, não quer dizer que por vezes, ainda que implicitamente, não se verifique a sua presença.

O primeiro obstáculo reside na dificuldade em se determinar a sua fonte, na medida em que existem diversas concepções pertinentes a ela. Talvez, a primeira ideia que emerja para o intérprete corresponda aos ideais iluministas, em que a fraternidade surgia como parte do tripé que se completa com a igualdade e com a liberdade. Mas por que estes outros dois princípios estão sempre tão presentes no ordenamento jurídico, enquanto a fraternidade passou por este processo de esquecimento? Pelo o que parece, os modelos de Estado que se seguiram desde as grandes revoluções do século XVIII, sobretudo com a formação do Estado Liberal, trouxeram junto com eles o fortalecimento do conceito de propriedade, o que remete à dimensão social de liberdade e igualdade. $\mathrm{O}$ foco deste estudo não está na tentativa de se distinguir, tampouco estabelecer qual a relação entre igualdade e liberdade, embora este seja tema de extrema relevância e que sempre se demonstra instigante. 


\section{Personalidade Acadêmica Homenageada:}

Carlos Aurélio Mota de Souza (Universidade Ibirapuera - UNIB)

Ma sim descobrir, em que medida a fraternidade é aplicável hoje, nos ordenamentos juridicos diversos, sobretudo, para efeitos do presente estudo aos concernentes a Estados integrantes do Acordo Schengen. Dessa forma, cumpre destacar qual o impacto da fraternidade na relação entre povos, pois esta inter-relação depende da forma como esta incide em suas relações e em como o Estado tutela esta coexistência, o que será tratado mais adiante.

Através da releitura do conceito de fraternidade, entende-se que a sua aplicabilidade corresponde a uma nova visão do ser humano, ou a uma visão abandonada por determinado período, que é a do ser humano real, concreto, o qual se reaproxima do ser humano em abstrato. Parece óbvio que esta leitura deve ser conjugada, mas esse casamento não se demonstra constante no tratamento dado às pessoas, ao menos não em sua totalidade. Pois isso implica em querer dar reais condições de igualdade entre elas, na medida em que não se olha para o outro como apenas como "o outro", mas se volta ao outro como "o outro como eu mesmo", através de uma expansão de consciência capaz de tocar o lado humano de cada parte envolvida nas relações de convívio.

Nesta perspectiva, Gisela Maria Bester e Eliseu Raphael Venturi tratam o humanismo jurídico como instituto que vai além do Direito, pois não se resume a relações jurídicas uma vez que, ao contrário, o seu alcance supera as fronteiras da norma legal, permeando também a ética e a filosofia geral, para além, é claro, de outros campos do conhecimento, a exemplo da medicina. Por outro lado, a sua importância para o pensamento jurídico é imensurável. Assim explicam:

\footnotetext{
Assim, uma visão humanista do mundo é imprescindível ao raciocínio jurídico, desde que compreendida nas esteiras de uma tutela humana total e incondicional obtida por meio do implemento das categoria de direitos da personalidade, direitos fundamentais e direitos humanos, dos quais todos são titulares, assim como dos microssistemas protetivos e dos princípios sempre presentes, como o da dignidade da pessoa humana e da regra de interpretação pro homine, todos inspirados pela pretensaão de atingimento de um bem-estar social e individual.
}

\footnotetext{
${ }^{1}$ BESTER, Gisela Maria; VENTURI, Eliseu Raphael. Cosmovisão Humanista na Constitutividade do Homo Juridicus Contemporâneo: elementos de uma hermenêutica jurídica humanizante. In: Ensaios de Direito e de Sociologia a Partir de Brasil e de Portugal: Movimentos, Direitos e Instituições. Curitiba: Instituto Memória, 2015. P-257.
} 


\title{
Personalidade Acadêmica Homenageada:
}

Carlos Aurélio Mota de Souza (Universidade Ibirapuera - UNIB)

Nota-se, portanto, que a leitura conjugada de categorias distintas de direitos, mas que convergem para finalidades semelhantes, surge como base da interpretação humanista do Direito, porque está a tutelar o ser humano, o qual desponta como núcleo de proteção jurídica, seguindo os autores com o raciocínio²:

\begin{abstract}
A regra de interpretação pro homine pode ser destacada neste contexto como elemento fundamental de concretização e efetividade dos direitos, uma vez que sua expressa recomendação é a de que se realize a interpretação de modo a maximizar o regime jurídico protetivo do indivíduo, agregando-lhe o máximo de garantias e proteção de direitos em determinado caso concreto sob apreço.
\end{abstract}

Ao se tratar de direitos do ser humano, inevitável é a relação óbvia com o princípio da dignidade da pessoa humana. Este, por sua vez, remete a aquele que talvez seja o mais importante dos direitos, que é o direito à vida. Desse modo, colaciona-se o ensinamento trazido por Marcos Keel Pereira, como segue ${ }^{3}$

\begin{abstract}
O STJ, em 26.4.95, frisou que o direito à vida é uma "irrecusável conquista civilizacional", sem o qual não se entenderia, hoje, na nossa cultura, a própria $\mathrm{DPH}$. Este direito é, segundo o tribunal, de cariz superior, porque inerente à qualidade humana, devendo (à partida) prevalecer sobre outros direitos, embora sempre se diga que tal prevalência apenas terá de verificar-se, no concreto, "se for caso disso e na medida do adequado".
\end{abstract}

Não restam dúvidas de que a Dignidade da Pessoa Humana, amparada pelo Direito Humanitário, guarda profunda pertinência com o Direito Fraterno, mantendo um forte intuito de preservação da vida de todos os indivíduos e, em última análise, dos povos dos quais estes são pertencentes.

Para Guilherme Mucelin e Sandra Regina Martini, a presença do princípio da fraternidade, ainda que pouco percebida, se faz de maneiras diversas, "mediante a efetivação e ampliação, por exemplo, do princípio da vulnerabilidade, uma vez que nele não há uma definição estanque, comportando um entrelaçamento dos direitos entre si

\footnotetext{
2 lbid: 271.

3 PEREIRA, Marcos Keel. O Lugar do Princípio da Dignidade da Pessoa Humana na Jurisprudência dos Tribunais Portugueses. Faculdade de Direito da Universidade Nova de Lisboa: Working Paper 4/02. P-12.
} 


\section{Personalidade Acadêmica Homenageada:}

Carlos Aurélio Mota de Souza (Universidade Ibirapuera - UNIB)

e para as exigências sociais para a tutela das pessoas concretas mais débeis em qualquer relação jurídica"4.

Esta noção de vulnerabilidade é uma das perspectivas diante das quais a fraternidade pode ser incorporada às relações jurídicas e sociais, pois é nela que se desperta outro aspecto fundamental para que o Direito Fraternal ganhe sentido. Está a se falar em solidariedade. E é fácil imaginar o sucesso da nova realidade diante da qual um estrangeiro, principalmente quando se depara com a verdade de outro país, de cultura tão diversificada, e quando nele adentra com o intuito de permanência, pois assim escolhe para que possa ter uma nova vida, depende da boa receptividade daqueles que 0 abriga.

Em relação aos direito inerentes à pessoa, em especial em seu vínculo com o Estado e com outros povos, vale destacar a rica contribuição inserida por Emmanuel Kant a partir de sua obra denominada de "À Paz Perpétua", na qual o autor estratifica o Direito em interno de um lado, e aquele o qual resolve chamar de Direito das gentes, do outro. O primeiro guarda pertinência com o ordenamento jurídico de determinado Estado, numa relação ampla ligada ao funcionamento estatal. O segundo, classifica como sendo aquele que tutela a relação entre o Estado e os indivíduos que o integra, bem como na inter-relação entre os indivíduos. Mas existe, conforme Kant, outra categoria jurídica, a qual define como Direito Cosmopolita. Neste, as relações estendem-se a toda a humanidade. Sobre a classificação de Kant, Soraya Nour explica ${ }^{5}$ :

O direito cosmopolita, direito dos cidadãos do mundo, que considera cada indivíduo não membro de seu Estado, mas membro, ao lado de cada Estado, de uma sociedade cosmopolita. A relação deste direito com os dois anteriores segue a tábua das categorias da Crítica da Razão Pura: um único Estado corresponde à categoria da unidade; vários Estados, no direito das gentes, à categoria da pluralidade; todos os seres humanos e os Estados no direito cosmopolita, à categoria da totalidade sistemática, que une os dois estados anteriores.

\footnotetext{
${ }^{4}$ MUCELIN, Guilherme; MARTINI, Sandra Regina. A Fraternidade como meio de reconhecimento da vulnerabilidade social no Direito contemporâneo. In: O Direito Entre a Fraternidade e a Complexidade. Porto Alegre: FAPERGS. 2018. P-23.

${ }^{5}$ NOUR, Soraya. À Paz Perpétua de Kant: Filosofia do Direito Internacional e das Relações Internacionais. São Paulo: Martins Fontes, 2013. P-55.
} 


\section{Personalidade Acadêmica Homenageada:}

Carlos Aurélio Mota de Souza (Universidade Ibirapuera - UNIB)

A paz, portanto, para Kant, depende desse terceiro estágio, o qual se refere ao mundo como um sistema que apresenta a ideia de unidade entre povos e nações. Sem qualquer dúvida, este é um conceito de extrema aderência à concepção de sociedade fraterna e aos temas relacionados à circulação de pessoas, sendo de grande valia o seu destaque nos estudos pertinentes às relações interpessoais.

Não cabe, portanto, apenas aos Estados desenvolverem políticas sociais para recepcionar outros povos, e sim de um movimento solidário coletivo em face da vulnerabilidade daqueles que buscam um novo espaço longe de seu país de origem.

Como bem definem Martini e Mucelin, "a proposta do Direito Fraterno reside, justamente, na busca de valorização dessa humanidade em oposição à desumanidade"6. Nota-se, portanto, que existe uma verdadeira preocupação, não só com o convívio entre as pessoas, mas com o verdadeiro bem estar de cada um que compõe a relação no caso concreto.

Todos esses conceitos estão intimamente ligados à noção de dignidade humana, princípio fundamental presente nas constituições dos Estados Democráticos de Direitos. A Constituição da República Portuguesa, em seu artigo 1ํ, faz previsão do princípio da dignidade da pessoa humana, o que Ihe dá respaldo constitucional, estando assim previsto, servindo como exemplo:

Portugal é uma República soberana, baseada na dignidade da pessoa humana e na vontade popular e empenhada na construção de uma sociedade livre, justa e solidária.

Nota-se que o artigo primeiro da Constituição Portuguesa prevê a dignidade da pessoa humana em consonância com a solidariedade a ser promovida não só pelo Estado, mas também pela sociedade.

O que se têm, ao contrário da fraternidade e da solidariedade, são o egoísmo e o individualismo, muitas vezes atribuídos ao formato consumerista da sociedade, mas que se estende às demais relações jurídicas. Sobre isso, Glaucia Cardoso Teixeira Torres e Tânia Lobo Muniz afirmam que "assim, cada vez mais, imerso em

\footnotetext{
${ }^{6}$ Ibidem, 24.
} 


\section{Personalidade Acadêmica Homenageada:}

Carlos Aurélio Mota de Souza (Universidade Ibirapuera - UNIB)

seu próprio mundo e, muitas vezes, esgotado com suas infindáveis 'necessidades', sobra pouco espaço intelectual para que se pense nas agruras do mundo contemporâneo"7. Portanto, uma sociedade egoísta fecha-se para as questões entre particulares, ou seja, embora esteja ocorrendo com o vizinho, a sua vida social não é comprometida, fazendo com que feche os olhos para problemas que na verdade permeiam a coletividade. Ao contrário, pensando como parte do todo, certo fragmento, imbuído do espírito solidário, perceberá, também, que os problemas que o cercam pertencem a toda a sociedade. O egoísmo cega, não permitindo que a sociedade evolua, pois o outro mantém-se apenas como o outro, de modo que não se percebe que o outro a ele se assemelha. Ao contrário, o que se percebe é a existência de uma sociedade que tem no olhar do próximo um diferente prisma, e que é igualmente legítimo, deixando de valorar através dos aspectos daquele que é julgado diferente.

Seguindo este raciocínio, Ingrid Zanella Andrade Campos e Clarindo Epaminondas de Sá Neto tratam a igualdade e a liberdade como elementos insuficientes diante de determinados quadros em que se necessita a observância das particularidades do caso concreto, em que determinado grupo social fica a depender dos demais para que a sua dignidade permaneça inabalada, por meio do acolhimento na coletividade ${ }^{8}$. E seguem afirmando que "é nessa falência que a fraternidade ressurge como demanda jurídica e sobremaneira, como demanda social a ressignificar a ideia sobre cidadania política e, sobretudo, de cidadania sexual ${ }^{9}$. A riqueza e lucidez com que o trecho transcrito corrobora com a importância do princípio da fraternidade fortalece o objetivo de se estender a relação fraternal e solidária para todos os campos do relacionamento social, em especial para aqueles capazes de gerar um profundo impacto jurídico e social, como são os casos envolvendo o debate entorno da questão de gênero e da inclusão daqueles que se enquadram nestas situações que exigem o acolhimento da coletividade, pois, ao contrário, permanecem em condições de

\footnotetext{
7 TORRES, Glaucia Cardoso Teixeira; MUNIZ, Tânia Lobo. Assimetrias Econômicas e os Princípios da Solidariedade e da Fraternidade Como Base Valorativa para se Enfrentamento. Revista Jurídica: V.2, N. 39. Curitiba: 2015. P-161.

8 CAMPOS, Ingrid Zanella Andrade; NETO, Clarindo Epaminondas de Sá. A Cidadania Sexual Fraterna: Por Uma Concepção de Dignidade para as Pessoas Trans. Revista Jurídica: V. 1, N. 50. Curitiba: 2018. P-227.

${ }^{9}$ Ibidem, 227.
} 


\section{Personalidade Acadêmica Homenageada:}

Carlos Aurélio Mota de Souza (Universidade Ibirapuera - UNIB)

vulnerabilidade, o que acaba por frustrar a proposta do Direito Fraterno. Para Vanessa Kerpel Chincoli, "a partir do momento que vemos o outro por meio de nós mesmos, possível fazer novos pactos fraternos, e os modos de resolução de conflitos são, certamente, um ideal caldo de cultura para a realização desse objetivo"10.

O Direito Fraterno é, portanto, mecanismo de inclusão capaz de diminuir as desigualdades e de recolocar aqueles que se encontram em situação de vulnerabilidade em sua condição plena de cidadão, independente de sua proveniência, assegurando, dessa forma, a sua dignidade enquanto ser humano capaz de manter relações jurídicas e sociais, em toda a sua complexidade, por meio da humanização, por muitas vezes abandonada e marginalizada pela própria sociedade em que está inserido.

Considerado o que até aqui foi exposto, segue-se adiante com a proposta de se demonstrar o vínculo entre o Direito Fraterno e as comunidades muçulmanas residentes no Brasil, de maneira a demonstrar que a liberdade e a igualdade só podem ganhar respaldo quando a humanização se faz presente. Para que o Direito Fraterno ganhe o respaldo do Direito como um todo e que exerça a força que dele se espera, a dependência do amparo da sociedade demonstra ser primordial, pois sem o seu apoio, as ações do Estado que visem 0 acolhimento de outros povos permanece enfraquecido. Portanto, aqueles grupos, que em um primeiro momento demonstram estar em posição de vulnerabilidade, podem neutralizar o sentimento de deslocamento social quando acolhidos pelos demais.

\section{O DIREITO FRATERNO E A CIRCULAÇÃO DE PESSOAS NA EUROPA}

\footnotetext{
${ }^{10}$ CHINCOLI, Vanessa Kerpel. A Importância do Direito Fraterno na Sociedade Contemporânea e na Resolução dos Conflitos Sociais. In: O Direito entre a Fraternidade e a Complexidade. Porto Alegre: FAPERGS, 2018. P- 37.
} 


\section{Personalidade Acadêmica Homenageada:}

\section{Carlos Aurélio Mota de Souza (Universidade Ibirapuera - UNIB)}

Tema de constante debate é o concernente à circulação de pessoas na Europa. É natural que os objetivos do Acordo de Schengen ${ }^{11}$ ainda causem estranheza para aqueles que não vivem na Europa, mesmo porque a sua proposta chama a atenção por se tratar de relação de convívio entre cidadãos de Estados distintos. Portanto, antes de mais nada, deve-se procurar entender em que contexto o acordo surgiu para que se possa compreender os caminhos que levam os países envolvidos ao desenvolvimento de um espaço comum. Inevitável, neste trajeto, é o encontro com as novas perspectivas mundiais, as quais podem promover alterações profundas nos intentos erigidos pelo tratado.

Trata-se de um acordo firmado em 1985 na localidade de Schengen, em Luxemburgo por, inicialmente, cinco membros da União Europeia, quais sejam, Alemanha, França, Bélgica, Países Baixos e Luxemburgo (a união desses três últimos é conhecida como BENELUX desde a formação da União Europeia). A primeira informação relevante é a de que, embora tenha sido inicialmente formado a partir de membros da união, com esta não se confunde, pois é um acordo que, ainda que em consonância com a UE, refere-se a acordo que surgiu em paralelo e que dele nasceu uma área de circulação comum, o qual ficou conhecido como Espaço Schengen.

O propósito é o de permitir a livre circulação de países signatários, sendo que atualmente, dos 30 Estados-membros, 27 são Estados integrantes da UE, correspondendo a quase sua totalidade (exceção da Irlanda e do Reino Unido), contando ainda com três Estados que não fazem parte da UE, sendo eles a Islândia, a Noruega e a Suíça. Conta ainda com quatro Estados que estão em fase de implementação: Chipre, Bulgária, Romênia e Liechenstein.

A Comissão Europeia trata do tema na seguinte perspectiva:

A livre circulação de pessoas é um direito fundamental garantido pela UE aos seus cidadãos. Permite a todos os cidadãos da UE viajar, trabalhar e viver em qualquer país da UE sem formalidades especiais. A cooperação Schengen reforça esta liberdade ao permitir que os cidadãos atravessem fronteiras internas sem serem submetidas a controlos nas fronteiras. $O$ espaço Schengen, sem fronteiras, garante a livre circulação para mais de

\footnotetext{
11 Comissão Europeia. https://ec.europa.eu/home-affairs/what-we-do/policies/borders-and-
} visas/schengen_en 


\title{
Personalidade Acadêmica Homenageada:
}

Carlos Aurélio Mota de Souza (Universidade Ibirapuera - UNIB)

400 milhões de cidadãos da UE, bem como para muitos cidadãos de países terceiros, empresários, turistas ou outras pessoas legalmente presentes no território da UE.

Fica claro que a circulação de pessoas é garantida para cidadãos naturais dos países signatários. Sabe-se, no entanto, que relações conflituosas podem facilmente surgir a partir na internacionalização de fronteiras, ainda mais em momentos de extrema delicadeza, como se dá nos dias atuais, tendo em vista a crise mundial de refugiados e outras questões envolvendo imigrantes legais e ilegais. Entretanto, estes temas de grande relevância para a comunidade internacional não serão tratados no presente trabalho, o qual propõe, neste momento, demonstrar como o Direito Fraterno irriga as relações entre cidadãos de diferentes Estados, conforme já vem sendo abordado desde o capítulo anterior.

O que se coloca em prova nesta relação entre povos é a manutenção da ordem e da paz, pois, embora os objetivos de manutenção do Espaço Schengen sejam nobres, a discussão sobre soberania nacional e direitos dos cidadãos emergem no âmbito de debate.

Axel Honneth bem explicita as nuances das relações sociais, em especial as dificuldades e obstáculos advindos de situações conflituosas, quando trata da luta por reconhecimento, como segue ${ }^{12}$ :

\begin{abstract}
As formas de reconhecimento do direito e da estima social já representam um quadro moral de conflitos sociais, porque dependem de critérios socialmente generalizados, segundo o seu modo funcional inteiro; à luz de normas como as que constituem o princípio da imputabilidade moral, ou as representações axiológicas sociais, as experiências sociais de desrespeito podem ser interpretadas e apresentadas como algo capaz de afetar potencialmente também outros sujeitos.
\end{abstract}

Diante deste viés, conclui-se ser árduo o exercício em direção à harmonia, à solidariedade e à sociedade fraterna. Os conflitos se dão em todos em todos os sistemas. Seguindo a concepção de Foucault, segundo a qual não existe poder centralizado, e sim diversos sistemas a se ordenarem, a relação entre povos teria vida

12 HONETH, Axel. Luta por Reconhecimento: a gramática moral dos conflitos sociais. São Paulo: Editora 34, 2017. 


\title{
Personalidade Acadêmica Homenageada:
}

Carlos Aurélio Mota de Souza (Universidade Ibirapuera - UNIB)

própria para sobreviver além da soberania dos Estados. Nos espaços comuns, portanto, existe um organismo repleto de formas de exercício de poder: ${ }^{13}$

\begin{abstract}
Quero dizer que em uma sociedade como a nossa, mas no fundo em qualquer sociedade, existem relações de poder múltiplas que atravessam, caracterizam e constituem o corpo social e que estas relações de poder não podem se dissociar, se estabelecer nem funcionar sem uma produção, uma acumulação e um funcionamento do discurso.
\end{abstract}

Chega-se a algumas conclusões no que tange o poder do Estado, considerando a separação de poderes e o poder da própria coletividade. Primeiro, que o Estado não detém um poder centralizado, do qual paririam todas as relações que estariam subordinadas a ele. Pelo contrário, o próprio poder estatal tem que se dividir em funções, diante das quais são estipulados limites as suas prerrogativas. E em segundo lugar, talvez a anotação mais importante até aqui. Se a estruturação do Estado é decorrência da vontade de satisfação da coletividade, então é dela que nasce o poder, o que não quer dizer que haja no povo um poder absoluto, mas que este também, em última análise participa da ampla divisão de poderes.

O que se quer demonstrar, é que a fraternidade não depende exclusivamente da vontade estatal. Ao contrário, são os próprios cidadãos capazes de acolher e permear a amorosidade entre as sociedades. Quando os Estados acolhem grupos sociais diversos, tudo o que estão a fazer é dar vida ao Direito Fraterno e Cosmopolita. O Direito Internacional, desse modo e no que tange a circulação de pessoas, é campo aberto para a semeadura da paz.

Por outro lado, os Estados podem fazer da recepção dos povos, impulso para o seu próprio crescimento, sem que para isso haja sacrifício de Direitos Humanos e nem supressão de Direitos Fundamentais. Parece ser mais lógico, sobretudo nos dias atuais, o sucesso pela abertura de fronteiras, de modo evidentemente ordenado e que garanta a segurança para os Estados e para as sociedades que nele se inserem, do

${ }^{13}$ FOUCAULT, Michel. Microfísica do Poder. São Paulo: Graal, 2009. P-179. 


\title{
Personalidade Acadêmica Homenageada:
}

Carlos Aurélio Mota de Souza (Universidade Ibirapuera - UNIB)

que se falar em expansão de território. Neste sentido, Francis Bacon lecionou em seus Ensaios Sobre Moral e Política: ${ }^{14}$

\begin{abstract}
Jamais, em toda história, um Estado naturalizou tão facilmente estrangeiros quanto Roma e constata-se que sua fortuna correspondeua essa prudente prática, já que seu império chegou a ser o maior que o mundo conheceu. Não esqueciam o que se denomina jus civitatis em sua mais lata significação, ou seja, não apenas jus comercii, jus conubii, jus haereditatis, mas também jus sufragii e jus petitionis sive honorum. E conferiam esses direitos não a uma pessoa em particular, mas à famílias e cidades e por vezes à nações inteiras, acrescendo a isso o costume de fundar colônias entre os outros povos.
\end{abstract}

Talvez a concepção de Bacon acerca da dimensão do Império Romano e de seus feitos não sejam mais absolutos. Mas o importante é a lição que se deixa sobre a convivência entre povos com a chancela do Estado soberano.

As relações conflituosas, embora naturais e eternamente presentes em qualquer coletividade, podem adquirir um novo significado, ao passo em que se rompe com a ideia de submissão e destruição, ao mesmo tempo em que se vislumbra nelas a chance de desenvolvimento de um Direito Internacional humanitário e sustentável.

\section{CONCLUSÃO}

Após a análise proposta, percebeu-se que o Direito Fraterno permeia as diversas relações jurídicas nos mais variados âmbitos, na medida em que se volta para o desenvolvimento social por meio da ampliação da solidariedade, imbuído de um sentimento de fraternidade. Os sistemas jurídicos múltiplos também estão presentes quando se trata de Direito Internacional e a relação entre povos e culturas diversas. Os Estados visam garantir esse núcleo de Direitos, sem deixar de se atentar para a soberania, o que não quer dizer que a harmonia entre nações e seus povos não possa prevalecer.

${ }^{14}$ BACON, Francis. Ensaios Sobre Moral e Política. Bauru: Edipro, 2001. P-104. 
Personalidade Acadêmica Homenageada:

Carlos Aurélio Mota de Souza (Universidade Ibirapuera - UNIB)

Em outra perspectiva, a análise do Direito Fraterno aplicado aos estrangeiros em livre circulação de pessoas entre os Estados signatários do Acordo de Schengen, demonstra êxito não só nas relações privadas, como também por iniciativa do Estado, seja através de políticas públicas, do papel fundamental do Legislador ou da tutela jurisdicional.

O que não quer dizer que não haja uma barreira, não física, mas de consciência, capaz de promover conflitos entre comunidades distintas no tocante à soberania dos Estados. No entanto, fica evidenciado também que a possibilidade de crescimento e desenvolvimento humanitário não fica adstrito ao campo dos sonhos, mas transforma-se em meta, na medida em que os mesmos Estados promovem a união de seus povos em consonância e em direção a um mesmo vértice, que é o da paz entre sociedades fraternas.

\section{REFERÊNCIAS}

BACON, Francis. Ensaios Sobre Moral e Política. Bauru: Edipro, 2001.

BESTER, Gisela Maria; VENTURI, Eliseu Raphael. Cosmovisão Humanista na Constitutividade do Homo Juridicus Contemporâneo: elementos de uma hermenêutica jurídica humanizante. In: Ensaios de Direito e de Sociologia a Partir de Brasil e de Portugal: Movimentos, Direitos e Instituições. Curitiba: Instituto Memória, 2015.

Comissão Europeia. Schengen Area. https://ec.europa.eu/home-affairs/what-wedo/policies/borders-and-visas/schengen en

CAMPOS, Ingrid Zanella Andrade; NETO, Clarindo Epaminondas de Sá. A Cidadania Sexual Fraterna: Por Uma Concepção de Dignidade para as Pessoas Trans. Revista Jurídica: V. 1, N. 50. Curitiba: 2018.

ASSEMBLÉIA DA REPÚBLICA. Constituição da República de Portugal (2015). Disponível em: https://www.parlamento.pt/Legislacao/Paginas/ConstituicaoRepublicaPortuguesa.asp $\underline{x}$.

ONU. Declaração Universal dos Direitos Humanos. Disponível em: http://www.onu.org.br/img/2014/09/DUDH.pdf 
Personalidade Acadêmica Homenageada:

Carlos Aurélio Mota de Souza (Universidade Ibirapuera - UNIB)

HONETH, Axel. Luta por Reconhecimento: a gramática moral dos conflitos sociais. São Paulo: Editora 34, 2017.

MUCELIN, Guilherme; MARTINI, Sandra Regina. A Fraternidade como meio de reconhecimento da vulnerabilidade social no Direito contemporâneo. In: O Direito Entre a Fraternidade e a Complexidade. Porto Alegre: FAPERGS. 2018.

NOUR, Soraya. À Paz Perpétua de Kant: Filosofia do Direito Internacional e das Relações Internacionais. São Paulo: Martins Fontes, 2013.

PEREIRA, Marcos Keel. O Lugar do Princípio da Dignidade da Pessoa Humana na Jurisprudência dos Tribunais Portugueses. Faculdade de Direito da Universidade Nova de Lisboa: Working Paper 4/02.

TORRES, Glaucia Cardoso Teixeira; MUNIZ, Tânia Lobo. Assimetrias Econômicas e os Princípios da Solidariedade e da Fraternidade Como Base Valorativa para se Enfrentamento. Revista Jurídica: V.2, N. 39. Curitiba: 2015. 